\title{
Reaction times, learning, and executive functioning in adults born preterm
}

\author{
Julia Suikkanen*1,2 $^{*}$, Satu Miettola ${ }^{1}$, Kati Heinonen ${ }^{3}$, Marja Väääsmäki ${ }^{4,5}$, Marjaana Tikanmäki ${ }^{1,5}$, \\ Marika Sipola ${ }^{1,5}$, Hanna-Maria Matinolli ${ }^{1,6}$, Marjo-Riitta Järvelinn ${ }^{7,8,9,10}$, Katri Räikkönen ${ }^{3}$, Petteri \\ Hovi $^{1,2}$, Eero Kajantie ${ }^{1,2,5,11}$
}

${ }^{1}$ Department of Public Health Solutions, National Institute for Health and Welfare, Helsinki and Oulu, Finland

${ }^{2}$ Children's Hospital, Pediatric Research Center, University of Helsinki, Helsinki University Hospital, Helsinki, Finland

${ }^{3}$ Department of Psychology and Logopedics, University of Helsinki, Helsinki, Finland

${ }^{4}$ Children, Adolescents and Families Unit, Department of Welfare, National Institute for Health and Welfare, Oulu, Finland

${ }^{5}$ PEDEGO Research Unit, MRC Oulu, Oulu University Hospital and University of Oulu, Oulu, Finland

${ }^{6}$ Department of Child Psychiatry, University of Turku, Turku, Finland

${ }^{7}$ Department of Epidemiology and Biostatistics, MRC-PHE Center for Environment \& Health, School of Public Health, Imperial College London, London, United Kingdom

${ }^{8}$ Center for Life Course Epidemiology, Faculty of Medicine, University of Oulu, Oulu, Finland

${ }^{9}$ Biocenter Oulu, Oulu, Finland 
${ }^{10}$ Unit of Primary Care, Oulu University Hospital, Oulu, Finland

11 Department of Clinical and Molecular Medicine, Norwegian University of Science and Technology, Trondheim, Norway

*Corresponding author

Julia Suikkanen, c/o Eero Kajantie, National Institute for Health and Welfare, Department of Public Health Solutions, P.O. Box 30, FI-00271 Helsinki, Finland; Phone: +358-29-524-6000; Email: julia.suikkanen@helsinki.fi

Author contributions: All authors (J.S., S.M., K.H., M.V., M.T., M.S., H-M.M., M-R.J., K.R., P.H., and E.K.) made substantial contributions to conception and design, acquisition of data, or analysis and interpretation of data as well as to drafting the article or revising it critically for important intellectual content. All authors approved the final version of the manuscript.

Statement of financial support: Supported by the Academy of Finland (SALVE program for 20092012 and grants $127437,129306,130326,134791,263924$, and 315690 to E.K., grants 323910 to K.H., 1312670 to K.R., and 288966 to P.H.); the European Commission (Horizon 2020 Award SC1-2016-RTD-733280 RECAP to E.K. and K.R.); the European Commission (Dynamics of Inequality Across the Life-course: structures and processes (DIAL) No. 724363 PremLife to E.K. and K.R.); the Doctoral Program for Public Health, University of Tampere (to M.S.); the Emil Aaltonen Foundation (to E.K.); the Finnish Foundation for Pediatric Research (to E.K. and P.H.); the Jalmari and Rauha Ahokas Foundation (to E.K.); the Juho Vainio Foundation (to E.K., M.T., and J.S.); the Novo Nordisk Foundation (to E.K.); the Signe and Ane Gyllenberg Foundation (to 
E.K. and K.R.); the Sigrid Jusélius Foundation (to E.K.); and the Yrjö Jahnsson Foundation (to E.K. and M.S.). The funding sources played no role in the design of the study, the collection, analysis, interpretation, or reporting of data, or the decision to submit the manuscript for publication.

Disclosure statement: The authors have no conflicts of interest to disclose.

Patient consent statement: All participants provided written informed consent.

Category of the study: Clinical Research Article

Key points of the article:

- Although preterm birth is a risk for the developing brain, adults born preterm as a group showed similar cognitive performance to their full-term peers

○ Children born preterm across gestational ages show defects in cognitive domains. With a supportive environment, many of them have the potential to catch up with those born at term.

- The unfavorable effect of late preterm birth on cognitive functions in childhood may not persist to adulthood; in this study, adults born late preterm showed similar cognitive functioning to adults born full-term

- The deficits in cognitive function in adults born preterm detected by earlier studies mainly concern those born the smallest, i.e. very preterm or preterm and small for gestational age 


\section{Abstract}

Background:

This study examines cognitive functioning in adults born across the range of prematurity with appropriate or small for gestational age (SGA) birth weight compared with full-term controls.

Methods:

ESTER Preterm Birth Study participants without severe disabilities, comprising 133 early preterm ( $<34$ weeks, $17 \%$ SGA), 241 late preterm $(34+0-36+6$ weeks, 13\% SGA), and 348 full-term subjects, performed the Cogstate ${ }^{\circledR}$ test at a mean age of $23.3(\mathrm{SD}=1.2)$ years. Subtests measured paired associate learning, psychomotor function, executive function, spatial memory efficiency, visual memory, attention, working memory, visual learning, and emotional cognition. Data were analyzed with linear regression, full models adjusted for pre- and postnatal factors and socioeconomic position.

Results:

Early preterm, late preterm, and full-term participants showed similar abilities in almost all subtests. Early preterm participants had 0.6 fewer moves/10 s (95\% CI: $-1.0 ;-0.2$, full model) and late preterm \& SGA participants 1.3 fewer moves/10 s (95\% CI: -2.1, -0.4) than full-term controls in the Groton Maze Learning Test, indicating weaker spatial memory efficiency.

\section{Conclusion:}

Adults born across the range of prematurity on average lack major defects in cognitive abilities. Cognitive problems may persist to adulthood only among those born the smallest: very preterm or preterm \& SGA. 


\section{Introduction}

Preterm birth ( $<37$ gestational weeks) predisposes to several long-term health problems, including cognitive defects and higher risk of mental health problems (1-3). Preterm children learn motor skills later and perform worse in mathematics and reading at school than their term peers, and they score lower in cognitive tests in childhood and also in young adulthood (2, 4-7). However, most of the extensive research on cognitive ability has focused on the smallest and most premature: very or extremely preterm ( $<32$ or $<28$ gestational weeks), or very or extremely low birth weight (VLBW; $<1500 \mathrm{~g}$ or $<1000 \mathrm{~g}$ birth weight) children. Cognitive defects among these groups are well established $(7,8)$ and are accompanied by deficits in executive functioning (9-12), comprising active and intentional cognitive processes, including controlling thoughts, behavior, and emotions (13). Very preterm children and adults as a group display lower intelligence; in two separate metaanalyses, they achieved an approximately 0.8 to 0.9 SD lower IQ than those born at term $(7,8)$.

Infants born late preterm ( $34+0$ to $36+6$ gestational weeks) constitute the majority of all preterm infants $(72 \%$ in the USA and $85 \%$ worldwide $)(14,15)$. Among toddlers and school-age children, those born late preterm have a higher risk for developmental disabilities, a greater need for special education, and worse performance in cognitive tests than those born at term (16-19). Few studies have reported any cognitive test results for adults born at the more mature end of prematurity, as recently reviewed elsewhere (20). In two Scandinavian studies of male military conscripts, higher gestational age was correlated with better intellectual performance at 18 to 19 years of age (21, 22). In our previous Arvo Ylppö Longitudinal Study cohort, young adults born late preterm did not differ from full-term controls in Full-Scale, Verbal, and Performance IQ tests after adjustments for peri- and postnatal factors and socioeconomic position (23). Only those born both late preterm 
and small for gestational age (SGA) performed more poorly than full-term controls in the FullScale and Performance IQ tests (23). We also showed in the Helsinki Birth Cohort Study that those born late preterm performed worse in word list recognition in the Consortium to Establish a Registry for Alzheimer's Disease Neuropsychological Battery (CERAD-NB) in late adulthood (mean age 68.1 years), and further, if having only attained basic or upper secondary education, had worse performance in several other subtests of CERAD-NB (24).

Our previous work with the Helsinki Study of Very low Birth Weight Adults (HeSVA) showed that adults born VLBW had slower reaction times and impaired learning relative to full-term controls in the computer-based Cogstate test (5). Our aims in this study were to evaluate reaction times, learning, and executive functioning in adults born over the entire range of prematurity with an updated and broader version of the Cogstate test, and to examine whether SGA birth weight (when combined with prematurity) is an additional risk factor for worse performance.

\section{Methods}

Participants

This study is part of the ESTER Preterm Birth Study in which we invited 1980 young adults from Northern Finland via the Northern Finland Birth Cohort 1986 (NFBC, born in 1985-1986; 49.8\%) and the Finnish Medical Birth Register (FMBR, born in 1987-1989; 50.2\%) to participate (25). In 2009-2011, 753 adults with verified durations of gestation participated in a clinical examination (Figure 1) (25). All participants provided written informed consent, and the study was approved by the Coordinating Ethics Committee of the Helsinki and Uusimaa Hospital District. We excluded 15 participants because of severe mental disability, cerebral palsy, or other severe physical disability. Another 16 participants were excluded from analyses because they did not finish all 
tasks or had outliers in several tasks that indicate poor compliance. Therefore, the current study finally included 722 participants ( $48 \%$ men): 133 (47\% men) early preterm $(<34$ gestational weeks) participants, 241 ( $49 \%$ men) late preterm (34+0 to $36+6$ gestational weeks) participants, and 348 (48\% men) full-term controls ( $\geq 37$ gestational weeks) (Table 1). In one of the Cogstate tasks (Groton Maze Learning Recall Test), data were only available for a subset of 72 early preterm participants, 133 late preterm participants, and 186 full-term controls.

Perinatal data

For the NFBC, perinatal data were previously collected from medical records deposited in the cohort database (26). We obtained corresponding data for the FMBR participants from the medical records of hospitals and maternity clinics (25). Duration of gestation was confirmed from these data (ultrasonography before 20 gestational weeks had been performed on $62.7 \%$ and $53.1 \%$ of the preterm infants and full-term controls, respectively) (25). Diagnosis of maternal hypertension (chronic or gestational), preeclampsia, and gestational diabetes was confirmed based on standard criteria $(27,28)$. Participants whose SD score for birth weight was less than -2.0 , according to the Finnish infant growth standards from the year 1989 (29), were classified as SGA, and all others were classified as appropriate for gestational age (AGA).

\section{Clinical examination}

Clinical examination was performed at a mean age of 23.3 (SD 1.2) years. Height and weight were measured and body mass index (BMI) was calculated (25). Participants filled in a questionnaire on medical history, medication, socioeconomic position, and lifestyle. Childhood socioeconomic position was defined by the highest parental educational attainment at the time of clinical examination (25). 
Cognitive assessment: Cogstate test

Cogstate Research ${ }^{\mathrm{TM}}$ is a computer-based cognitive test battery previously used in several different settings to test mild cognitive impairments $(30,31)$. To evaluate reaction times and cognitive functioning in general, we chose the Continuous Paired Associate Learning Test, Detection Test, Groton Maze Learning (GML) Test, Identification Test, One Card Learning Test, One Back Test, and Social Emotional Cognition Test for the battery (the tasks are explained below). Before testing, a research nurse (blinded to the birth status) issued oral instructions and all of the participants practiced at least once, as recommended; more than one training session rarely improves the results (32). During testing the participants were alone at the computer and wore headphones so that they could hear the error beep for incorrect answers. Written instructions were provided on the screen before each task, and familiarization trials were performed with visual and auditory feedback for correct/incorrect answers before the real test. The whole test lasted 9.18 to 15.07 minutes. The test results were transferred as encrypted data files to the Cogstate server and automatic data extraction was performed.

Tasks at the Cogstate battery

Continuous Paired Associate Learning Test evaluates visual associative memory with number of errors. Different patterns are shown on the screen and the participants are required to find an identical pair forthe pattern shown. In the second round, the patterns are hidden and the participant needs to remember where they were earlier located on the screen.

Detection Test evaluates psychomotor function based on a simple measurement of mean reaction time. The participant must press any key immediately when a playing card turns face up. 
GML Test evaluates executive function based on the number of errors and as a secondary variable spatial memory efficiency based on the speed of correct movement (33). The participant searches for the correct route from one corner of a $10 \times 10$ grid of tiles to the opposite side. Only downwards or sideways movements are allowed, and only one step can be taken in each move. The same route is repeated five times. To test visual memory, executive function, and learning, the GML Recall Test (repetition of the GML Test) was performed after all the other tests and the number of errors was measured.

Identification Test evaluates visual attention based on the mean reaction time. Depending on whether they see a red or black playing card, the participant needs to press the red or black key as quickly as possible.

One Back Test evaluates working memory according to speed of correct movement. In this test, two cards are displayed and the participant presses "yes" or "no" depending on whether the card they have seen is the same as the previous one.

One Card Learning Test evaluates visual learning according to the accuracy of performance (the portion of correct hits from all responses). The participant must press the "yes" or "no" key depending on whether they think the card shown was displayed before or not.

Social Emotional Cognition Test evaluates emotional cognition based on the accuracy of performance. Photographs of four faces are shown and the participant needs to recognize which of the faces is different from the other three.

Statistical analysis 
First, we visually inspected the Cogstate data for outliers and inconsistencies. Multiple linear regression models were used to detect differences between those born early preterm, late preterm, and full-term, and all p-values below 0.05 were considered significant. The Cogstate program delivers results for time to make a correct movement (Detection Test, Identification Test, and One back Test) in milliseconds transformed to logarithms to base 10. Due to skewness of the distributions, we also transformed number of errors at GML, GML Recall, and Continuous Paired Associate Learning Tests to the logarithm scale after adding one error for each participant (because some participants had zero errors). Results of accuracy of performance in the One Card Learning and Social Emotional Cognition Tests were delivered and analyzed in arcsine square root proportion values as per Cogstate standard. All logarithmic and arcsine square root proportion values were back-transformed after analysis so the results for these variables are shown as percentage differences between the groups.

Regression model 1 was adjusted for the source cohort (NFBC or FMBR), sex, and age. Model 2 was further adjusted for birth weight SD score, maternal smoking during pregnancy, maternal BMI before pregnancy, maternal hypertension or preeclampsia, maternal diabetes, mother's age, being first-born, and parental education (at the time of clinical examination). These variables for adjustment were selected based on theoretical grounds $(5,34,35)$. We also analyzed whether adjustment for birth head circumference SD score, adult head circumference, or physical activity in adulthood would have an effect on the results; none of these affected the models, and thus, they were omitted from the final models.

The analyses were also performed in the following pre-defined subgroups: early preterm \& SGA $(n=22)$, late preterm \& SGA $(n=31)$, early preterm \& AGA $(n=111)$, late preterm \& AGA $(n=210)$, 
and those born VLBW (n=42), compared with those born full-term \& AGA $(n=341)$. The design of our study was based on performing the analyses in early preterm and late preterm subgroups, but to investigate the linear effect of gestational age we also carried out the analyses with gestational age as a continuous variable (the analyses included preterm participants). IBM SPSS Statistics 24 was used to perform the analyses.

\section{Results}

Characteristics

The early and late preterm groups differed from the full-term controls in terms of their pre- and postnatal factors, including birth size, being born as a twin, and maternal preeclampsia (Table 1). The early preterm group included $17 \%(\mathrm{n}=22)$, the late preterm group $13 \%(\mathrm{n}=31)$, and the fullterm control group $2 \%(\mathrm{n}=7)$ of SGA participants. The late preterm participants were more likely to be born from a mother with gestational diabetes than the full-term controls: $11(5 \%)$ of those born late preterm versus $6(2 \%)$ of the full-term controls $(\mathrm{p}=0.04)$. A detailed non-participant analysis has been previously presented (25). Of the unimpaired adults who were excluded from analyses because they did not complete the Cogstate test (or had several outliers) $(n=16), 6$ were born early preterm (of these individuals, 1 was also born SGA), 6 were born late preterm, and 4 were born full-term. Because of the small size of this excluded group, a full non-participant analysis of them is not shown.

Cogstate test results

The early and late preterm participants performed similarly to those born full-term in most of the Cogstate tasks (Table 2): Continuous Paired Associate Learning Test, Detection Test (which measures psychomotor function), Identification Test (attention), One Card Learning Test (visual 
learning), One Back Test (working memory), and Social Emotional Cognition Test. The difference estimates between the early and late preterm groups and full-term controls were between $0 \%$ and 13\% (with large CIs, including zero) when adjusted for sex, age, and source cohort (Model 1, Table 2). The results remained similar after adjusting the models for several perinatal and postnatal factors and parental socioeconomic position (Model 2).

The only test that showed any significant differences between the groups was the GML Test (Table 2). Those born early preterm were slower than those born at term; this indicates that the early preterm group had lower spatial memory efficiency (33). The difference remained both in Model 1 (adjusted for sex, age, and cohort) and after further adjustments for pre- and postnatal factors and parental socioeconomic position in Model 2 ( 0.6 fewer correct moves/10 s, 95\% CI: -1.0, -0.2, Model 2). However, the early preterm group had a similar number of errors as the full-term controls in the same test (measuring executive function) (Table 2). The late preterm group was also slower than the full-term control group in the GML Test, with 0.3 fewer correct moves $/ 10 \mathrm{~s}$ (95\% CI: $-0.6,-0.0)$ in Model 1. However, the difference became non-significant after further adjustments in Model 2. In the GML Recall Test (measuring visual memory and executive function), the early preterm group had $27.5 \%(95 \% \mathrm{CI}: 5.6,53.8)$ and the late preterm group 17.7\% (95\% CI: $0.9,37.2)$ more errors than the full-term controls in Model 1, but the results were attenuated after further adjustments in Model 2.

In the analyses of predefined subgroups of early preterm \& SGA, late preterm \& SGA, early preterm \& AGA, late preterm \& AGA, and VLBW compared with those born full-term \& AGA, again barely any differences appeared (Supplemental Table S1 (online), and Table 3). All groups performed similarly to the full-term \& AGA controls in the Continuous Paired Associate Test, 
Detection Test, Identification Test, One Card Learning Test, One Back Test, and Social Emotional Cognition Test (Supplemental Table S1 (online)). However, in the GML Test, although there were no differences in the number of errors (executive function), the speed of performance (spatial memory efficiency) was slower in early preterm \& AGA ( 0.7 fewer correct moves/10 s, 95\% CI: $-1.1 ;-0.2$, Model 2), late preterm \& SGA (1.3 fewer correct moves/10 s, 95\% CI: $-2.1 ;-0.4$, Model 2), and VLBW groups (1.1 fewer correct moves/10 s, 95\% CI: - $1.9 ;-0.3$, Model 2) than in the full-term \& AGA controls (Table 3). The early preterm \& AGA and VLBW groups also had more errors than the full-term \& AGA group in the GML Recall Test (visual memory and executive function): $25.1 \%$ (95\% CI: 1.1, 54.9) and 62.5\% (95\% CI: 10.0; 139.9, Model 2) more errors, respectively.

In the analyses using gestational age as a continuous variable (including participants born preterm), nearly similar results were shown as when divided into gestational age groups, and no significant associations were detected for the majority of the tasks (Supplemental Table S2 (online)).

\section{Discussion}

We showed that unimpaired adults born early and late preterm performed, on average, as well as full-term controls in almost all of the tested core cognitive abilities: paired associate learning, psychomotor function, attention, visual learning, working memory, and emotional cognition. These results did not support our hypothesis of milder cognitive weaknesses among adults born at the mature end of prematurity. The only exception was the speed of performance in the GML Test, which measures spatial memory efficiency (33); the early preterm participants had 0.6 fewer correct moves/10 s (95\% CI: -1.0, -0.2) than full-term controls, translating to $0.3 \mathrm{SD}$ effect size, 
and late preterm \& SGA participants had 1.3 fewer correct moves/10 s (95\% CI: -2.1; -0.4) than full-term \& AGA controls, translating to $0.7 \mathrm{SD}$ effect size.

Previous findings by us and others have extensively shown that even adults without major disabilities who were born very preterm or VLBW perform worse on traditional neurocognitive tests than those born full-term, including lower IQ and lower scores in attention scales $(2,3,7)$. One of the characteristics of the profile of VLBW/very preterm adults is difficulty in executive functioning (9-12), i.e. the functions necessary for the cognitive control of behavior and selecting and successfully monitoring behaviors that facilitate the attainment of chosen goals (13). Here, we have hypothesized that these problems would be manifested, to some extent, also in those adults born closer to term. The number of errors in the GML Test represents mostly executive function (especially error monitoring), and speed in the same test represents spatial memory efficiency (33). In the present study, those born early and late preterm had a similar number of errors, but were slower than full-term controls in the GML Test. For those born late preterm, the statistical significance was marginal and arose from the slower speed among those born late preterm \& SGA. Those born with VLBW were also slower than full-term \& AGA controls in the GML Test. The analyses further indicate that VLBW and early preterm \& AGA participants made more errors in the GML Recall Test (repeat of the GML Test as a measure of visual memory and executive function). Overall, these test results are consistent with the spatial memory problems detected in adults born preterm, but among those born late preterm the weaknesses were only observed among those born SGA.

Spatial memory is used for remembering one's environment and orientation of objects relative to each other, helping us to interact with them (36). Problem solving often requires spatial memory 
functions, and children with poorer spatial memory may face difficulties in problem-solving tasks at school (37). This could partly explain the challenges that preterm individuals have in mathematics $(37,38)$. Although specific mechanisms behind the spatial memory problems of preterm children are poorly known (36), a Norwegian study found smaller hippocampi in VLBW young adults, which was related to poorer visual memory indices on the Wechsler Memory Scale (39). Children born late preterm appear to have lower intellectual ability and higher risk for school difficulties than those born at term (17-19). Intellectual ability in adulthood has also been assessed by register studies that used intellectual ability tests for military conscripts in Sweden and Norway during an era when military service was obligatory for all men. These studies show that lower intellectual ability in men born preterm is sustained in adulthood $(21,22)$. However, in the Swedish study, those born at 35 to 36 and 33 to 34 gestational weeks showed only $0.06 \mathrm{SD}$ and $0.09 \mathrm{SD}$ lower intellectual ability, respectively, than those born at term in adjusted models (22). In the Norwegian study, the corresponding differences were merely $0.05 \mathrm{SD}$ for those born late preterm and $0.13 \mathrm{SD}$ for those born at 30 to 33 gestational weeks (21). Such small differences would not have been detected in the present study in which the width of CIs corresponded to around 0.3 to $0.5 \mathrm{SD}$.

Our previous study with the Arvo Ylppö Longitudinal Study included late preterm subjects who needed medical care in the neonatal ward within 10 days of birth (23). Therefore, the participants were, in infancy, likely to be sicker than the late preterm group in the present study, which as a geographical cohort also included infants healthy enough to stay with their mother (23). In that study, the late preterm participants showed slight weaknesses in the Full-Scale, Verbal and Performance IQ tests; they had 0.25 SD (3.7 IQ points) lower full-scale IQ than those born at term (23). This difference was explained partly by socioeconomic and perinatal factors, but findings 
remained for those born both late preterm and SGA, among whom the full-scale IQ was 1.1 SD (11.8 IQ points) lower than in full-term controls (23). In the present study, the late preterm and full-term participants performed mostly similarly in the Cogstate test (with CIs of -0.1 to 0.4 SD), but the difference in speed in the GML Test of late preterm participants and full-term controls remained after adjustments for confounding factors in those born late preterm \& SGA, with an effect size of 0.7 SD. These findings suggest SGA as an additional risk factor, in particular among those born late preterm with lower immaturity-associated risk.

Computer-based simple tasks measure partly different abilities (e.g. reaction time and accuracy as important measurements) than traditional neurocognitive tests (41); this might explain why we did not distinguish differences in most of the tests. Moreover, our previous findings in the HeSVA cohort showed that those born VLBW and preterm had slower reaction times in all of the five tasks performed (including three tasks similar to those in the present study: the Detection Test, the Identification Test, and the One Back Test called Simple reaction time, Choice reaction time, and One back working memory, respectively, in the previous publication) (5). However, these findings were not replicated in the present study even in the VLBW group, although the speed of performance on the GML Test may correlate with reaction time and learning (33). The effect sizes for reaction times in the Detection Test, Identification Test, and One Back Test were 0.2 to 0.4 in the previous study (5). The point estimates for the same tests were 0.1 to $0.3 \mathrm{SD}$ (with CIs including zero, when adjusted for sex, age, and cohort) in the present study for the comparison between VLBW and full-term \& AGA adults. In the present study, the number of those born VLBW was small (42 versus 147), and they also had a slightly higher mean gestational age (30.4 versus 29.2 weeks) than the HeSVA cohort (5). Overall, even the early preterm group in this cohort had a higher mean gestational age $(31.9$ weeks, $\mathrm{SD}=1.9)$ than pure very preterm cohorts (i.e. cohorts 
only including infants born VLBW or <32 gestational weeks), which may explain the mildness of the differences between those born early preterm and at term.

One of the main strengths of this study is the large number of participants $(n=722)$ born across a wide range of gestational ages. The cohort was selected from a geographical region, and thus, it also includes healthy late preterm adults not needing treatment at the neonatal care unit. We have collected detailed neonatal data and information about pregnancy disorders, maternal smoking, and childhood socioeconomic position, allowing adjustments with multiple important covariates. The cognitive test used, the computer-based Cogstate, has both strengths and limitations. It is a standardized test battery that is independent of research personnel, but its retest reliability might be low (42). Further, the validity of the different tasks relative to traditional cognitive tests has been divergent, as interclass correlations ranging from weak to very high have been demonstrated $(43,44)$. Combining the Cogstate test with traditional cognitive testing would have increased the reliability of our results. Limitations of our cohort include having no data on cognitive testing at earlier time points. Moreover, although we were able to adjust for a number of important covariates, we may not have accounted for all confounding factors as a result of the long followup period. Finally, we cannot completely rule out participation bias, although no relevant differences in the characteristics between participants and non-participants were detected, as previously presented in detail (25).

Preterm birth has been associated with several long-term problems, including defects in cognitive functions at different ages $(4,6,8)$. However, the majority of the findings have been presented in studies that include only those born the most immature: very preterm or VLBW. We showed that in a population-based cohort of unimpaired young adults born over the whole range of gestational 
ages cognitive performance of those born early and late preterm attained the level of those born full-term. Although this study cannot exclude small differences, it appears that cognitive weaknesses established in childhood among those born at the mature end of prematurity may not persist to adulthood in those without comorbidities. However, SGA may be an additional risk factor for cognitive problems in adulthood among those born late preterm. 


\section{References}

1. Pyhälä R, et al. Self-Reported Mental Health Problems Among Adults Born Preterm: A Metaanalysis. Pediatrics 2017;139(4):10.1542/peds.2016-2690. Epub 2017 Mar 10

2. Pyhälä R, et al. Neurocognitive abilities in young adults with very low birth weight. Neurology 2011;77(23):2052-2060

3. Breeman LD, Jaekel J, Baumann N, Bartmann P, Wolke D. Attention problems in very preterm children from childhood to adulthood: the Bavarian Longitudinal Study. J Child Psychol Psychiatry 2016;57(2):132-140

4. Lee M, Pascoe JM, McNicholas CI. Reading, Mathematics and Fine Motor Skills at 5 Years of Age in US Children who were Extremely Premature at Birth. Matern Child Health J 2017;21(1):199-207

5. Strang-Karlsson S, et al. Slower reaction times and impaired learning in young adults with birth weight

6. Allotey J, et al. Cognitive, motor, behavioural and academic performances of children born preterm: a meta-analysis and systematic review involving 64061 children. BJOG 2018;125(1):16-25

7. Twilhaar ES, et al. Cognitive Outcomes of Children Born Extremely or Very Preterm Since the 1990s and Associated Risk Factors: A Meta-analysis and Meta-regression. JAMA Pediatr 2018;172(4):361-367

8. Brydges CR,et al. Cognitive outcomes in children and adolescents born very preterm: a metaanalysis. Dev Med Child Neurol 2018;60(5):452-468

9. Heinonen K, et al. Self- and parent-rated executive functioning in young adults with very low birth weight. Pediatrics 2013;131(1):243

10. Solsnes AE, Skranes J, Brubakk AM, Lohaugen GC. Executive functions in very-low-birthweight young adults: a comparison between self-report and neuropsychological test results. J Int Neuropsychol Soc 2014;20(5):506-515

11. Nosarti C, et al. Impaired executive functioning in young adults born very preterm. J Int Neuropsychol Soc 2007;13(4):571-581

12. Stalnacke J, Lundequist A, Bohm B, Forssberg H, Smedler AC. A longitudinal model of executive function development from birth through adolescence in children born very or extremely preterm. Child Neuropsychol 2018:1-18 
13. Diamond A. Executive functions. Annu Rev Psychol 2013;64:135-168

14. Martin JA, Osterman MJK. Describing the Increase in Preterm Births in the United States, 2014-2016. NCHS Data Brief 2018;(312)(312):1-8

15. Chawanpaiboon $\mathrm{S}$, et al. Global, regional, and national estimates of levels of preterm birth in 2014: a systematic review and modelling analysis. Lancet Glob Health 2019;7(1):e37-e46

16. Johnson S, et al. Neurodevelopmental outcomes following late and moderate prematurity: a population-based cohort study. Arch Dis Child Fetal Neonatal Ed 2015;100(4):301

17. Lipkind HS, Slopen ME, Pfeiffer MR, McVeigh KH. School-age outcomes of late preterm infants in New York City. Am J Obstet Gynecol 2012;206(3):222.e1-222.e6

18. Chyi LJ, Lee HC, Hintz SR, Gould JB, Sutcliffe TL. School outcomes of late preterm infants: special needs and challenges for infants born at 32 to 36 weeks gestation. J Pediatr 2008;153(1):25-31

19. Talge NM, et al. Late-preterm birth and its association with cognitive and socioemotional outcomes at 6 years of age. Pediatrics 2010;126(6):1124-1131

20. Kajantie E, Strang-Karlsson S, Evensen KAI, Haaramo P. Adult outcomes of being born late preterm or early term - What do we know?. Semin Fetal Neonatal Med 2019;24(1):66-83

21. Eide MG, Oyen N, Skjaerven R, Bjerkedal T. Associations of birth size, gestational age, and adult size with intellectual performance: evidence from a cohort of Norwegian men. Pediatr Res 2007;62(5):636-642

22. Ekeus C, Lindström K, Lindblad F, Rasmussen F, Hjern A. Preterm birth, social disadvantage, and cognitive competence in Swedish 18- to 19-year-old men. Pediatrics 2010;125(1):67

23. Heinonen $\mathrm{K}$, et al. Neurocognitive outcome in young adults born late-preterm. Dev Med Child Neurol 2018;60(3):267-274

24. Heinonen K, et al. Late preterm birth and neurocognitive performance in late adulthood: a birth cohort study. Pediatrics 2015;135(4):818

25. Sipola-Leppänen $M$, et al. Cardiometabolic risk factors in young adults who were born preterm. Am J Epidemiol 2015;181(11):861-873

26. Sipola-Leppänen M, et al. Cardiovascular risk factors in adolescents born preterm. Pediatrics 2014;134(4):1072 
27. Miettola S, et al. Offspring's blood pressure and metabolic phenotype after exposure to gestational hypertension in utero. Eur J Epidemiol 2013;28(1):87-98

28. Vääräsmäki M, et al. Adolescent manifestations of metabolic syndrome among children born to women with gestational diabetes in a general-population birth cohort. Am J Epidemiol 2009;169(10):1209-1215

29. Pihkala J, Hakala T, Voutilainen P, Raivio K. Characteristic of recent fetal growth curves in Finland. Duodecim 1989;105(18):1540-1546

30. Darby D, Maruff P, Collie A, McStephen M. Mild cognitive impairment can be detected by multiple assessments in a single day. Neurology 2002;59(7):1042-1046

31. Cysique LA, Maruff P, Darby D, Brew BJ. The assessment of cognitive function in advanced HIV-1 infection and AIDS dementia complex using a new computerised cognitive test battery. Arch Clin Neuropsychol 2006;21(2):185-194

32. Falleti MG, Maruff P, Collie A, Darby DG. Practice effects associated with the repeated assessment of cognitive function using the CogState battery at 10-minute, one week and one month test-retest intervals. J Clin Exp Neuropsychol 2006;28(7):1095-1112

33. Pietrzak RH,et al. An examination of the construct validity and factor structure of the Groton Maze Learning Test, a new measure of spatial working memory, learning efficiency, and error monitoring. Arch Clin Neuropsychol 2008;23(4):433-445

34. Machin S, Pekkarinen T. Assessment. Global sex differences in test score variability. Science 2008;322(5906):1331-1332

35. Finkel D, Reynolds CA, McArdle JJ, Pedersen NL. The longitudinal relationship between processing speed and cognitive ability: genetic and environmental influences. Behav Genet 2005;35(5):535-549

36. Herweg NA, Kahana MJ. Spatial Representations in the Human Brain. Front Hum Neurosci 2018;12:297

37. Passolunghi MC, Mammarella IC. Spatial and visual working memory ability in children with difficulties in arithmetic word problem solving. European Journal of Cognitive Psychology 2010;22(6):944-963

38. Aarnoudse-Moens CS, Oosterlaan J, Duivenvoorden HJ, van Goudoever JB, WeisglasKuperus N. Development of preschool and academic skills in children born very preterm. J Pediatr 2011;158(1):51-56

39. Aanes S, Bjuland KJ, Skranes J, Lohaugen GC. Memory function and hippocampal volumes in preterm born very-low-birth-weight (VLBW) young adults. Neuroimage 2015;105:76-83 
40. Arthursson PSH, et al. Atypical neuronal activation during a spatial working memory task in 13-year-old very preterm children. Hum Brain Mapp 2017;38(12):6172-6184

41. Cole WR, et al. Test-retest reliability of four computerized neurocognitive assessment tools in an active duty military population. Arch Clin Neuropsychol 2013;28(7):732-742

42. MacDonald J, Duerson D. Reliability of a Computerized Neurocognitive Test in Baseline Concussion Testing of High School Athletes. Clin J Sport Med 2015;25(4):367-372

43. Resch JE, McCrea MA, Cullum CM. Computerized neurocognitive testing in the management of sport-related concussion: an update. Neuropsychol Rev 2013;23(4):335-349

44. Collie A, et al. CogSport: reliability and correlation with conventional cognitive tests used in postconcussion medical evaluations. Clin J Sport Med 2003;13(1):28-32 
Table 1. Characteristics of the participants.

\begin{tabular}{|c|c|c|c|c|}
\hline Neonatal characteristics & $\begin{array}{l}\text { Early } \\
\text { preterm, } \\
\text { N (\%) or } \\
\text { mean (SD) }\end{array}$ & $\begin{array}{l}\text { Late } \\
\text { preterm, } \\
\mathrm{N}(\%) \text { or } \\
\text { mean (SD) }\end{array}$ & $\begin{array}{l}\text { Full-term } \\
\text { controls, } \\
\mathrm{N}(\%) \text { or } \\
\text { mean }(\mathrm{SD})\end{array}$ & $\begin{array}{l}\text { Missing, } \\
\mathrm{N} \text {, } \\
\text { Early preterm/ } \\
\text { Late preterm/ } \\
\text { Full-term }\end{array}$ \\
\hline Number of participants & 133 & 241 & 348 & \\
\hline Men & $63(47 \%)$ & $117(49 \%)$ & $166(48 \%)$ & $0 / 0 / 0$ \\
\hline Gestational age, wk & $31.9(1.9)^{*}$ & $35,8(0.8)^{*}$ & $40.1(1.2)$ & $0 / 0 / 0$ \\
\hline Birth weight, $g$ & $1790(480)^{*}$ & $2670(520)^{*}$ & $3580(490)$ & $0 / 0 / 0$ \\
\hline Birth weight SD score & $-0.74(1.39)^{*}$ & $-0.64(1.28)^{*}$ & $-0.01(1.00)$ & $0 / 0 / 0$ \\
\hline Length at birth, $\mathrm{cm}$ & $42.1(3.1)^{*}$ & $46.7(2.4)^{*}$ & $50.4(2.0)^{*}$ & $22 / 12 / 0$ \\
\hline Small for gestational age $\mathrm{e}^{\mathrm{a}}$ & $22(17 \%)^{*}$ & $31(13 \%)^{*}$ & $7(2 \%)$ & $0 / 0 / 0$ \\
\hline $\begin{array}{l}\text { Head circumference at birth, } \\
\mathrm{cm}\end{array}$ & $30.1(2.3)^{*}$ & $33.2(1.5)^{*}$ & $35.1(1.4)$ & $34 / 31 / 3$ \\
\hline $\begin{array}{l}\text { Head circumference at birth } \\
\text { SD score }\end{array}$ & $-0.04(1.4)$ & $-0.06(1.1)$ & $-0.04(0.9)$ & $34 / 31 / 3$ \\
\hline Twins or triplets & $31(23 \%)^{*}$ & $33(14 \%)^{*}$ & $4(1 \%)$ & $0 / 0 / 0$ \\
\hline $\begin{array}{l}\text { Maternal smoking during } \\
\text { pregnancy }\end{array}$ & $20(15 \%)$ & $46(19 \%)$ & $57(16 \%)$ & $7 / 5 / 5$ \\
\hline $\begin{array}{l}\text { Hypertension (gestational or } \\
\text { chronic) }\end{array}$ & $17(13 \%)$ & $36(15 \%)$ & $36(10 \%)$ & $7 / 5 / 5$ \\
\hline Maternal preeclampsia & $32(24 \%)^{*}$ & $29(12 \%)^{*}$ & $16(5 \%)$ & $0 / 5 / 5$ \\
\hline Gestational diabetes & $4(3 \%)$ & $11(5 \%)^{*}$ & $6(2 \%)$ & $20 / 24 / 9$ \\
\hline First-born & $53(40 \%)$ & $106(44 \%)^{*}$ & $109(31 \%)$ & $0 / 0 / 0$ \\
\hline Maternal age, years & $29.0(5.4)$ & $28.6(6.1)$ & $28.1(5.5)$ & $0 / 0 / 0$ \\
\hline Maternal BMI, kg/m2 & $22.4(3.3)$ & $22.6(3.9)$ & $22.2(3.1)$ & $8 / 7 / 14$ \\
\hline Parental education & & & & $1 / 5 / 2$ \\
\hline Lower secondary & $13(10 \%)$ & $20(8 \%)$ & $20(6 \%)$ & \\
\hline Upper secondary & $78(59 \%)$ & $135(56 \%)$ & $212(61 \%)$ & \\
\hline Lower tertiary & $14(11 \%)$ & $31(13 \%)$ & $45(13 \%)$ & \\
\hline Upper tertiary & $27(20 \%)$ & $50(21 \%)$ & $69(20 \%)$ & \\
\hline \multicolumn{5}{|l|}{ At clinical study } \\
\hline Age & $23.1(1.4)^{*}$ & $23.1(1.3)^{*}$ & $23.6(1.1)$ & $0 / 0 / 0$ \\
\hline Height, cm, women & $163.5(5.2)$ & $164.7(5.5)$ & $163.9(5.9)$ & $0 / 0 / 0$ \\
\hline
\end{tabular}




$\begin{array}{lllll}\text { Height, cm, men } & 178.8(7.0) & 177.7(6.7) & 177.8(6.9) & 0 / 0 / 0 \\ \text { BMI, kg/m2 } & 24.2(4.7) & 24.5(4.5) & 23.8(3.9) & 0 / 0 / 0 \\ \text { Head circumference, cm } & 56.4(2.0) & 56.6(1.9) & 56.4(1.9) & 0 / 1 / 2\end{array}$

Early preterm means participants born $<34$ gestational weeks, late preterm 34+0-36+6 gestational weeks, and full-term $\geq 37$ gestational weeks.

*Statistically significant difference with full-term controls ( $\mathrm{p}$ value $<0.05$ with Student's t-test or Pearson's Chi-Square test)

${ }^{a}$ birth weight $<-2$ SD according to Finnish infant growth standards $1989^{35}$ 
Table 2. Cogstate test outcomes in preterm groups compared to those born at full-term.

\begin{tabular}{|c|c|c|c|c|c|c|c|}
\hline & $\begin{array}{l}\text { Full-term } \\
\text { controls, } \\
\text { Geometric } \\
\text { mean }^{\mathrm{a}}\end{array}$ & $\begin{array}{l}\text { Geometric } \\
\mathrm{SD}^{\mathrm{a}}, \%\end{array}$ & Model $^{\mathrm{b}}$ & $\begin{array}{l}\text { Early preterm. } \\
\text { Mean difference }, \% \\
(95 \% \mathrm{CI})\end{array}$ & $\mathrm{p}$ & $\begin{array}{l}\text { Late preterm. } \\
\text { Mean difference }, \% \\
(95 \% \mathrm{CI})\end{array}$ & $\mathrm{p}$ \\
\hline $\begin{array}{l}\text { Continuous Paired } \\
\text { Associate Learning } \\
\text { Test, number of } \\
\text { errors. }^{d}\end{array}$ & 15.4 & 184.6 & $\begin{array}{l}1 \\
2\end{array}$ & $\begin{array}{l}3.2(-16.9 ; 28.1) \\
-3.2(-23.8 ; 22.9)\end{array}$ & $\begin{array}{l}0.78 \\
0.79\end{array}$ & $\begin{array}{l}12.8(-5.5 ; 34.7) \\
8.7(-10.2 ; 31.6)\end{array}$ & $\begin{array}{l}0.18 \\
0.39\end{array}$ \\
\hline $\begin{array}{l}\text { Detection Test } \\
\text { (psychomotor } \\
\text { function), time for } \\
\text { making a correct } \\
\text { movement. }^{\mathrm{d}}\end{array}$ & $263.1 \mathrm{~ms}$ & 37.8 & $\begin{array}{l}1 \\
2\end{array}$ & $\begin{array}{l}-0.7(-7.3 ; 6.3) \\
1.1(-6.3 ; 9.0)\end{array}$ & $\begin{array}{l}0.84 \\
0.79\end{array}$ & $\begin{array}{l}2.9(-2.8 ; 8.9) \\
2.8(-3.3 ; 9.2)\end{array}$ & $\begin{array}{l}0.32 \\
0.38\end{array}$ \\
\hline $\begin{array}{l}\text { Groton Maze Learning } \\
\text { Test (executive } \\
\text { function), number of } \\
\text { errors. }^{d}\end{array}$ & 44.9 & 37.5 & $\begin{array}{l}1 \\
2\end{array}$ & $\begin{array}{l}4.5(-2.0 ; 11.4) \\
2.2(-4.7 ; 9.7)\end{array}$ & $\begin{array}{l}0.18 \\
0.54\end{array}$ & $\begin{array}{l}1.0(-4.2 ; 6.4) \\
-0.1(-5.6 ; 5.7)\end{array}$ & $\begin{array}{l}0.71 \\
0.96\end{array}$ \\
\hline $\begin{array}{l}\text { Groton Maze Learning } \\
\text { Test (spatial memory } \\
\text { efficiency), speed, } \\
\text { moves } / 10 \mathrm{~s} .\end{array}$ & $8.7^{f}$ & $1.9^{\mathrm{f}}$ & $\begin{array}{l}1 \\
2\end{array}$ & $\begin{array}{l}-0.7(-1.1 ;-0.3)^{\mathrm{f}} \\
-0.6(-1.0 ;-0.2)^{\mathrm{f}}\end{array}$ & $\begin{array}{l}<0.001 \\
0.005\end{array}$ & $\begin{array}{l}-0.3(-0.6 ;-0.0)^{\mathrm{f}} \\
-0.3(-0.6 ; 0.1)^{\mathrm{f}}\end{array}$ & $\begin{array}{l}0.04 \\
0.11\end{array}$ \\
\hline $\begin{array}{l}\text { Groton Maze Learning } \\
\text { Recall Test (visual } \\
\text { memory and } \\
\text { executive function), } \\
\text { number of errors. }\end{array}$ & 4.9 & 108.5 & $\begin{array}{l}1 \\
2\end{array}$ & $\begin{array}{l}27.5(5.6 ; 53.8) \\
20.6(-1.5 ; 47.7)\end{array}$ & $\begin{array}{l}0.01 \\
0.07\end{array}$ & $\begin{array}{l}17.7(0.9 ; 37.2) \\
10.3(-6.6 ; 30.2)\end{array}$ & $\begin{array}{l}0.04 \\
0.25\end{array}$ \\
\hline $\begin{array}{l}\text { Identification Test } \\
\text { (attention), time for } \\
\text { making a correct } \\
\text { movement. } \\
\end{array}$ & $407.3 \mathrm{~ms}$ & 16.8 & $\begin{array}{l}1 \\
2\end{array}$ & $\begin{array}{l}1.7(-1.8 ; 5.2) \\
0.3(-3.4 ; 4.2)\end{array}$ & $\begin{array}{l}0.35 \\
0.86\end{array}$ & $\begin{array}{l}2.4(-0.5 ; 5.3) \\
1.2(-1.9 ; 4.3)\end{array}$ & $\begin{array}{l}0.10 \\
0.45\end{array}$ \\
\hline $\begin{array}{l}\text { One Back Test } \\
\text { (working memory), } \\
\text { time for making a } \\
\text { correct movement. }\end{array}$ & $645.4 \mathrm{~ms}$ & 28.2 & $\begin{array}{l}1 \\
2\end{array}$ & $\begin{array}{l}3.8(-1.4 ; 9.2) \\
1.6(-3.9 ; 7.4)\end{array}$ & $\begin{array}{l}0.15 \\
0.57\end{array}$ & $\begin{array}{l}3.1(-1.1 ; 7.6) \\
1.1(-3.3 ; 5.8)\end{array}$ & $\begin{array}{l}0.15 \\
0.62\end{array}$ \\
\hline $\begin{array}{l}\text { One Card Learning Test } \\
\text { (visual learning), } \\
\text { accuracy of } \\
\text { performance. }^{\text {e }}\end{array}$ & $0.7^{\mathrm{g}}$ & $0.2^{g}$ & 1 & $-0.8(-4.2,0.1)^{g}$ & 0.14 & $\begin{array}{l}-0.8(-3.4,0.0)^{\mathrm{g}} \\
-0.7(3.6,0.0)^{\mathrm{g}}\end{array}$ & 0.06 \\
\hline $\begin{array}{l}\text { Social Emotional } \\
\text { Cognition Test, } \\
\text { accuracy of } \\
\text { performance. }^{\mathrm{e}}\end{array}$ & $0.8^{g}$ & $0.1^{g}$ & $\begin{array}{l}1 \\
2\end{array}$ & $\begin{array}{l}-0.0(-0.7,0.4)^{\mathrm{g}} \\
-0.0(-0.6,0.6)^{\mathrm{g}}\end{array}$ & $\begin{array}{l}0.74 \\
0.97\end{array}$ & $\begin{array}{l}-0.0(-0.4,0.3)^{\mathrm{g}} \\
-0.0(-0.5,0.3)^{\mathrm{g}}\end{array}$ & $\begin{array}{l}0.85 \\
0.97\end{array}$ \\
\hline
\end{tabular}

Early preterm refers to participants born at $<34$ gestational weeks; late preterm, $34+0$ to $36+6$ gestational weeks; and full-term, $\geq 37$ gestational weeks. 
${ }^{a}$ Geometric mean represents the back-transformed value of the arithmetic mean of logarithmic values, and geometric SD refers to the SD for the logarithmic values back-transformed to percentages.

${ }^{\mathrm{b}}$ Model 1 was adjusted for source cohort, sex and age. Model 2 was additionally adjusted for birth weight-SD, maternal smoking, maternal BMI, hypertension, preeclampsia, gestational diabetes, parental education, mother's age, and being first-born.

${ }^{\mathrm{c}}$ The test results were analyzed as logarithmically transformed values (due to the skewness of distributions) and were back-transformed to percentages after analysis.

${ }^{\mathrm{d}}$ Negative mean difference corresponds to better performance.

${ }^{\mathrm{e}}$ Positive mean difference corresponds to better performance.

${ }^{\mathrm{f}}$ Speed of performance in the Groton Maze Learning Test was analyzed using arithmetic values. The values are shown as moves/10 s.

g Mean and SD are arithmetic, accuracy represent the proportion of correct hits from all hits. The difference was analyzed as arcsine square root proportions and back-transformed to per mille after analysis. 
Table 3. Groton Maze Learning (GML) Test outcomes in subgroups according to gestational age and birth weight compared to full-term and appropriate for gestational age (AGA) controls.

\begin{tabular}{|c|c|c|c|c|c|c|c|}
\hline Subgroup & Model $^{\mathrm{a}}$ & $\begin{array}{l}\text { GML Test, number } \\
\text { of errors }{ }^{\mathrm{b}} \text {, executive } \\
\text { function, } \%(95 \% \\
\text { CI). Negative value } \\
\text { means better } \\
\text { performance. }\end{array}$ & $\mathrm{p}$ & $\begin{array}{l}\text { GML Test, speed, } \\
\text { spatial memory } \\
\text { efficiency, moves } \\
/ 10 \mathrm{~s}(95 \% \mathrm{CI}) \text {. } \\
\text { Positive value means } \\
\text { better performance. }\end{array}$ & $\mathrm{p}$ & $\begin{array}{l}\text { GML Recall Test, } \\
\text { number of errors }{ }^{\mathrm{b}} \text {, } \\
\text { visual memory and } \\
\text { executive function, } \% \\
(95 \% \mathrm{CI}) \text {. Negative } \\
\text { value means better } \\
\text { performance. }\end{array}$ & $\mathrm{p}$ \\
\hline $\begin{array}{l}\text { Very low birth } \\
\text { weight (VLBW) }\end{array}$ & 1 & $7.6(-3.1,19.4)$ & 0.17 & $-1.2(-1.8,-0.6)$ & $<0.001$ & $65.9(22.8,124.0)$ & 0.001 \\
\hline$(\mathrm{n}=42)$ & 2 & $1.0(-12.0,15.9)$ & 0.89 & $-1.1(-1.9,-0.3)$ & 0.01 & $62.5(10.0,139.9)$ & 0.01 \\
\hline $\begin{array}{l}\text { Early preterm \& } \\
\text { AGA } \\
(\mathrm{n}=111)\end{array}$ & $\begin{array}{l}1 \\
2\end{array}$ & $\begin{array}{l}4.6(-2.4,12.0) \\
5.1(-2.3,13.2)\end{array}$ & $\begin{array}{l}0.20 \\
0.18\end{array}$ & $\begin{array}{l}-0.6(-1.0 ;-0.2) \\
-0.7(-1.1,-0.2)\end{array}$ & $\begin{array}{l}0.002 \\
0.002\end{array}$ & $\begin{array}{l}27.7(4.7,55.9) \\
25.1(1.1,54.9)\end{array}$ & $\begin{array}{l}0.02 \\
0.04\end{array}$ \\
\hline $\begin{array}{l}\text { Early preterm \& } \\
\text { small for } \\
\text { gestational age } \\
(\text { SGA) } \\
(\mathrm{n}=22)\end{array}$ & $\begin{array}{l}1 \\
2\end{array}$ & $\begin{array}{l}6.7(-6.9,22.3) \\
-6.8(-21.8,11.0)\end{array}$ & $\begin{array}{l}0.35 \\
0.43\end{array}$ & $\begin{array}{l}-1.1(-1.9 ;-0.3) \\
-0.7(-1.8,0.3)\end{array}$ & $\begin{array}{l}0.005 \\
0.16\end{array}$ & $\begin{array}{l}44.2(-4.6,118.0) \\
31.7(-22.9,124.9)\end{array}$ & $\begin{array}{l}0.08 \\
0.31\end{array}$ \\
\hline $\begin{array}{l}\text { Late preterm \& } \\
\text { AGA } \\
(\mathrm{n}=210)\end{array}$ & $\begin{array}{l}1 \\
2\end{array}$ & $\begin{array}{l}1.6(-3.8,7.3) \\
0.6(-5.1 ; 6.6)\end{array}$ & $\begin{array}{l}0.57 \\
0.84\end{array}$ & $\begin{array}{l}-0.2(-0.5,0.1) \\
-0.2(-0.5,0.1)\end{array}$ & $\begin{array}{l}0.23 \\
0.23\end{array}$ & $\begin{array}{l}17.1(0.0,37.3) \\
11.5(-6.0,32.4)\end{array}$ & $\begin{array}{l}0.05 \\
0.21\end{array}$ \\
\hline $\begin{array}{l}\text { Late preterm \& } \\
\text { SGA } \\
(\mathrm{n}=31)\end{array}$ & $\begin{array}{l}1 \\
2\end{array}$ & $\begin{array}{l}0.5(-10.6,12.8) \\
-0.6(-13.8,14.7)\end{array}$ & $\begin{array}{l}0.94 \\
0.94\end{array}$ & $\begin{array}{l}-1.2(-1.8,-0.5) \\
-1.3(-2.1,-0.4)\end{array}$ & $\begin{array}{l}0.001 \\
0.003\end{array}$ & $\begin{array}{l}44.2(1.9,103.9) \\
42.1(-9.3,122.7)\end{array}$ & $\begin{array}{l}0.04 \\
0.12\end{array}$ \\
\hline
\end{tabular}

Early preterm refers to participants born at $<34$ gestational weeks; late preterm, $34+0$ to $36+6$ gestational weeks; and full-term, $\geq 37$ gestational weeks.

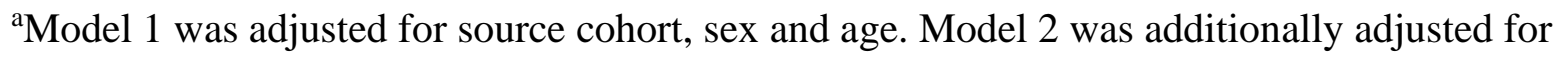
birth weight-SD, maternal smoking, maternal BMI, hypertension, preeclampsia, gestational diabetes, parental education, mother's age, and being first-born.

${ }^{b}$ The test results were analyzed as logarithmically transformed values (due to the skewness of distributions) and were back-transformed to percentages after analysis. 


\section{Figures}

Figure 1. Flow chart of study participants. Early preterm was defined as $<34$ gestational weeks, late preterm as $34+0$ to $36+6$ gestational weeks, and full-term as $\geq 37$ gestational weeks.

\begin{tabular}{|c|c|}
\hline \multicolumn{1}{|c|}{$\begin{array}{c}\text { Invited } \\
(\mathrm{n}=1980)\end{array}$} \\
\hline $\begin{array}{c}\text { Participated (gestational age confirmed) } \\
(\mathrm{n}=753)\end{array}$ \\
(149 early preterm, 248 late preterm, 356 full-term)
\end{tabular}

